\title{
Applying learning algorithms to extract anxiety levels using the heart rate variability measure
}

\author{
Marcio Magini*1, Izabela Mocaiber ${ }^{2}$, Kassio Calembo ${ }^{2}$, Maira Regina Rodrigues ${ }^{1}$, Welton Luiz de Oliveira Barbosa ${ }^{2}$, \\ Walter Machado-Pinheiro \\ ${ }^{1}$ Universidade Federal do Rio de Janeiro, Campus Macaé, Macaé, Brazil \\ ${ }^{2}$ Departamento de Ciências da Natureza, Instituto de Humanidades e Saúde, Campus Universitário de Rio das Ostras, \\ Universidade Federal Fluminense, Rio das Ostras, Brazil
}

Received: June 1, 2015

DOI: $10.5430 /$ jbgc.v5n2p9
Accepted: July 20, 2015

Online Published: July 28, 2015

URL: http://dx.doi.org/10.5430/jbgc.v5n2p9

\begin{abstract}
The classification problems in biological measures have been studied since mathematical methods and statistical tools were created to determine difference between two distinct samples. In this paper we present a mathematical methodology capable of differing 29 non-clinical volunteers with distinct degrees of trait anxiety (high or low) according to the State and Trait Anxiety Inventory (STAI-T) using an electrocardiogram (ECG) data as starting point. Specifically, the wavelet transforms and its statistical measures were used to extract simple patterns from the resting ECG and classify the group as low or high trait anxiety. The Daubechies, Haar and Symlet mother function were used to filter the original ECG data. Then, by means of the Weka Learning Algorithm and using only 5 attributes (Pearson Coefficient from Haar and Symlet, Median from Haar and Mode of Haar and Daubechies) we achieved a higher level of reliability, $96.90 \%(p<.05)$, with low training percentages. The results showed the efficiency of this methodology to classify volunteers according to their anxiety levels through an ECG data collection.
\end{abstract}

Key Words: Electrocardiogram, Learning algorithms, Anxiety, Wavelet, Variability

\section{Introduction}

The electrocardiogram (ECG) is an important complementary clinical test used to evaluate many physiopathological aspects in heart function. It can be also used to identify specific characteristics from the individuals which are not necessarily related with a physiological problem. Briefly, the ECG is the record of variations in the extracellular electrical potential of heart muscle activity. The depolarization and repolarization waves that propagate along the cardiac fibers can be considered moving dipoles variables that determine the electric fields. Thus, the potential generated by the heart during systole-diastole cycle (contrac- tion/relaxation) can be registered by measuring the potential difference across electrodes placed on the skin surface, according to pre-established guidelines. ${ }^{[1-3]}$ Registration is accomplished by measuring the difference in electrical potential between two points in the electric field generated by electric dipole heart during the cardiac cycle. The normal ECG consists of characteristics waves $(\mathrm{P}, \mathrm{Q}, \mathrm{R}, \mathrm{S}$ and $\mathrm{T}$ - see Figure $1^{[4]}$ ) which correspond to electrical events of myocardial activation and deactivation. Thus, the P-wave corresponds to atrial depolarization, the QRS-complex to ventricular depolarization T-wave and repolarization of the ventricles. $^{[4]}$

\footnotetext{
*Correspondence: Marcio Magini; Email: mmagini@macae.ufrj.br; Address: Universidade Federal do Rio de Janeiro, Campus Macaé, Macaé, Brazil. Av. Aluizio da Silva Gomes, 50-Granja dos Cavaleiros. Brazil. 
The study of the variability in the heart rate, or simply the heart rate variability (HRV) refers to the variation in intervals between heartbeats and is essentially based in the evaluation of the interval between two sequential $\mathrm{R}$-waves (the R-R interval). The R-R interval is the most common measure used to define some important aspects of the heart function and reflects cardiac autonomic modulation, physiologically influenced by increased parasympathetic activity. However, some physiological aspects related to HRV and other biological data are still under examination by biological and even mathematical researchers because sometimes, relevant information about HRV is related with complex aspects, which usually are difficult to extract directly from the original ECG data. In this sense, sometimes it is impossible to extract more detailed information from "raw data", such as the interval R-R. To minimize this question many studies reveal the importance of implementing new mathematical procedures in ECG analysis to identify relevant biological patterns. Most of these analyses include techniques of data compression searching for the better quality of the signal or to decompose it aiming to classify the differences between the heart rate variability in specific conditions. ${ }^{[5-8]}$ Statistical techniques are used to extract biological information about the volunteer conditions and tools like fuzzy algorithms or neural networks are common in these biological applications. In this vein, the most traditional technique to analyze the HRV signal is the Fourier Transform and Series. ${ }^{[9]}$ Specifically in biological data, many works using additional computational procedures and new techniques generate a complete system to process and analyze those data. ${ }^{[10-12]}$ Thus, artificial intelligence algorithms represent one of the most promising tools in this field of knowledge. They are capable of learning the main aspects of the data groups and extract from it some relevant patterns that represent core aspects of each group.

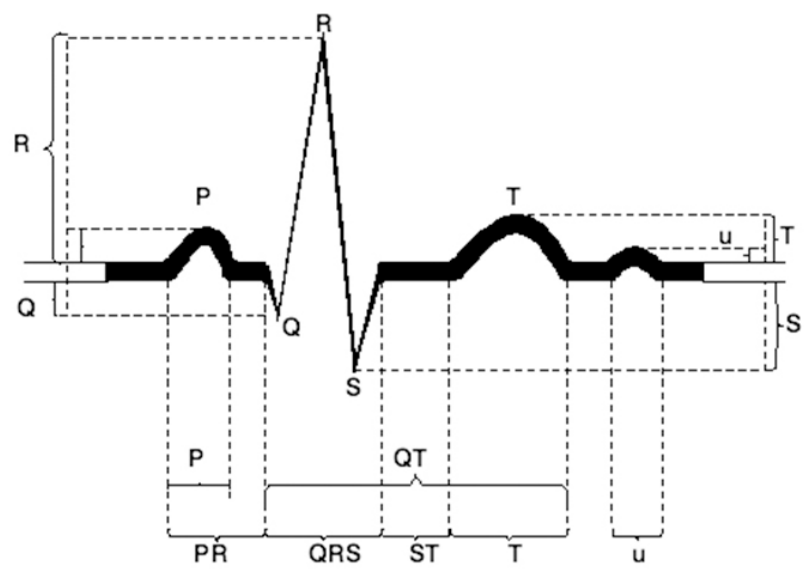

Figure 1: The ECG quantitative parameters ${ }^{[4]}$

In this study we tried to improve some mathematical techniques to extract patterns that could be useful to characterize risk groups or some specific pathology in order to prevent a worsening of cardiac condition. Specifically we asked whether HRV data could be used as a predictor of some psychological and individual condition, such as the anxiety level, or simply, the trait anxiety (TA). TA refers to individual differences (the level of anxiety) that are also considered a risk factor to elicit clinical anxiety states or anxiety disorders when confronted with situations perceived as threatening. TA has been also considered as an important predictor of cardiovascular disease. ${ }^{[13]}$

In a previous study of our group, ${ }^{[14]}$ the putative role of basal HRV as predictor of anxiety and affect levels was tested by means of wavelet transform tools in a non-clinical population of undergraduate students. Anxiety level (trait anxiety) was evaluated through Spielberg's State and Trait Anxiety Inventory (STAI-T) ${ }^{[15,16]}$ and positive and negative affect scores were measured through the Positive (PA) and Negative (NA) Affect Schedule (PANAS). ${ }^{[17]}$ The ECG data were analyzed solely using Wavelet Transform Daubechies order 4. Each psychological parameter (TA, PA and NA) was correlated with the values of frequency levels of HRV (high, low and ultra-low frequency) aiming to investigate if this mathematical approach would be able to characterize TA, PA and/or NA affect in our non-clinical population. A nonsignificant, although relevant, tendency between frequency level and psychological parameters were found, suggesting that HRV can be a promising predictor of anxiety and affective scores.

The present work, on the other hand, proposes a complete system of analysis of the ECG data collected in basal conditions and evaluates its capacity to determine the anxiety level of two different groups previously designed as low and high trait anxiety volunteers (LTA and HTA, respectively). Specifically, we were interested in verifying the efficiency of different algorithms of learning machine methods to identify both groups of volunteers having different psychological characteristics using a minimal number of parameters. The efficiency of our protocol in separating both groups using the ECG data and with a high level of reliability represents an additional and important result. For this purpose, an analysis of the ECG using wavelet transforms and statistical information were applied here. After that, a set of learning algorithms were adopted to create different scenarios. Five attributes were then processed by Weka (a machine learning based software). ${ }^{[18-24]}$

In the present study, to achieve the optimization of the results previously found we focused in an ECG analysis using wavelet transforms, statistical information and the original signal processed by LWL, J48, ADTree and RandomForest. These algorithms are inserted in Weka and have already been used in signal processing at different context/applications, as an open source software Weka has a high potential in many other applicantions. ${ }^{[18]}$ The importance of finding a reliable bio-mathematical predictor of trait 
anxiety lies in the fact that HTA individuals can be more vulnerable to develop clinical anxiety disorders and consequently are more exposed to the deleterious effects of this condition to the cardiovascular system. Thus, in the present study we explored the accuracy of a classification technique to correctly discriminate high and low anxiety traits based on the HRV spectrum parameters.

\section{Methods}

\subsection{Participants and questionnaires}

Thirty right-handed undergraduate students (15 female) with a mean age of 21.07 years $( \pm 1.68 \mathrm{SD})$ participated in this study. Volunteers were selected among students from the Federal Fluminense University, Brazil, and had normal or corrected-to-normal vision. They reported no psychiatric or neurologic problems and were not under medication with nervous system action. Participants were naive as to the purpose of the experiment. The local ethics committee approved the experiment, and participants gave informed consent. Participants were tested individually. On arrival, they completed the Portuguese trait section of the State and Trait Anxiety Inventory (STAI-T). This questionnaire is based in a standard form already used in clinical and non-clinical studies and consists of 20 short statements (e.g. "I feel afraid") rated on a four-point scale, from 1 to 4 (1 $=$ seldom/never and $4=$ very often/always), thus generating a score of values among 20 and 80 . Scores were used in order to characterize the sample in terms of TA levels: A high score indicates high levels of anxiety and a low score indicates low levels of anxiety. As mentioned, thirty participants were enrolled in the present study: from these, 11 individuals had score value above the mean and were classified as HTA; 18 individuals with scores below the mean were classified as LTA. Data from one participant was lost due to some technical problems. ${ }^{[14]}$

\subsection{Electrocardiogram}

After completing the questionnaires, participants were seated in a chair located in a sound attenuated and dimly lit experimental room. They were informed about the nature of the assessments and written consent was obtained. Physiological sensors were attached and signal quality was checked before starting the physiological recordings. Subjects were instructed to rest and breathe normally. A Biopac ECG recorder, model MP100, was used to record the electrocardiogram at lead II using silver/silver chloride electrodes with hypertonic electrolyte paste. Band filter of $0.5 \mathrm{~Hz}-35 \mathrm{~Hz}$ and sampling rate of $1,000 \mathrm{~Hz}$ were used. Baseline ECG was collected during 4 min. The HRV variability obtained in this baseline ECG was submitted to the wavelets transforms and statistical measures in the present study. ${ }^{[2,3,25]}$

Published by Sciedu Press

\subsection{Computational analysis}

\subsubsection{Wavelets}

The mother wavelets are functions capable of extracting some specific parameters of frequency from time evolution of a data set. Similar to Fourier transform analysis, the wavelets use non-harmonic functions to filter the signal and extract information about it. Because it is localized in the space, the wavelet transform generate a similar signal when compared with Fourier. The pre-requisites to allow the signal processing by wavelet are: signal must have finite energy and no offset. Actually, both requirements were achieved by our data.

It means that energy is finite and localized. Both characteristics are useful for HRV signals due to its dispersion. Usually the average value of the non-processed signal (HRV) is null. In this study we use three different discrete mother functions $\phi(\mathrm{t})$ : Haar, Symlet and Daubechies. For example, Haar function is constructed mathematically by:

$$
\left\{\begin{array}{cl}
0 & t<0 \\
1 & 0<t<1 / 2 \\
-1 & 1 / 2<t<1 \\
0 & t>1
\end{array}\right.
$$

On the other hand, Daubechies and Symlet, related by symmetry considerations, have no explicit expression and as well the Fast Fourier Transform, all of them work as a filter for the HRV. Therefore, these three mother functions were used in this study as a prior filter.

\subsubsection{WEKA algorithms}

Machine learning algorithms LWL, J48, ADTree and RandomForest from the Weka collection were used for testing. Two sets of information were constructed using the SMOTE and Resample filters. The learning methodology adopted was the PercentageSplit with percentages values of $66 \%$, $75 \%$ and $85 \%$. For each percentage and HRV sample, the algorithms were executed 100 times in a random way to generate different initial values. Moreover, a pre-processed analysis had already been implemented (the wavelet filters) and from that, algorithms capable of extracting more precise information were generated from a set of five (5) attributes to distinguish differences between groups. Those attributes were: the Pearson Variation Coefficient extract from the Wavelet transform signal for two mother functions, Haar and Symlet; Median from the Haar Wavelet Transform; Modes from Haar and Daubechies Wavelet Transforms. Examples of pre-processed signal and its graphical results are shown in Figures 2, 3 and 4.

Specifically in Figure 4 the Daubechies analysis generated three different levels of decomposition: high frequency (HF), low frequency (LF) and ultra-low frequency (ULF) which represent, respectively, the interval from 140 to 270 (HF), 70 to 140 (LF) and 0 to 70 (ULF). 


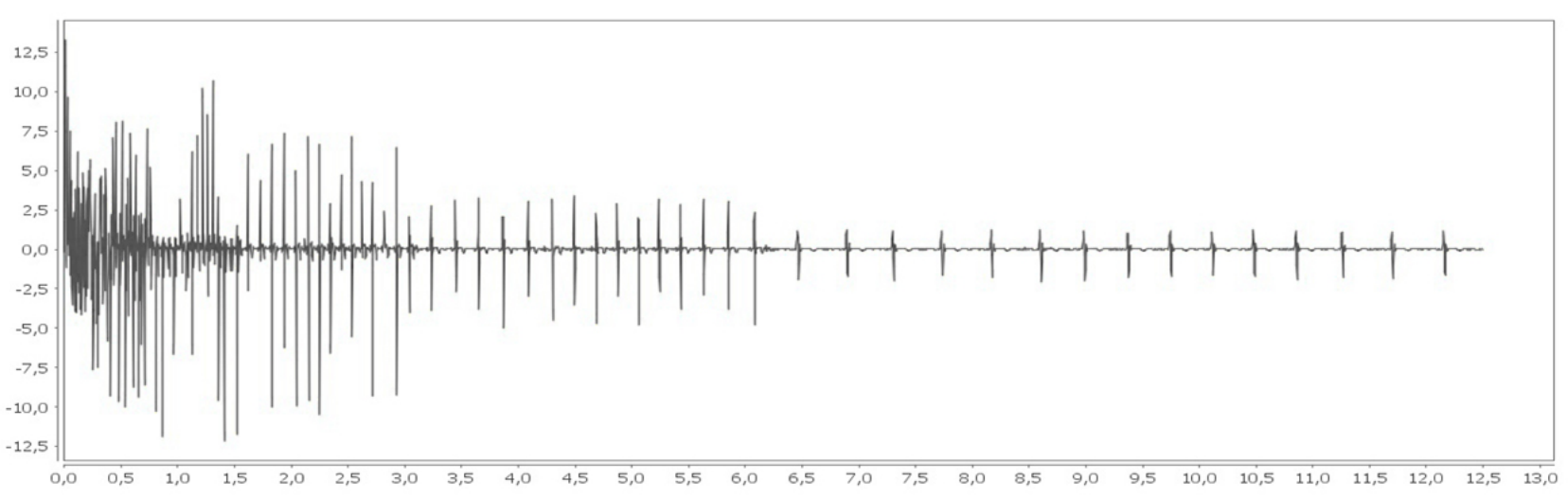

Figure 2: The Haar function from the ECG data 1

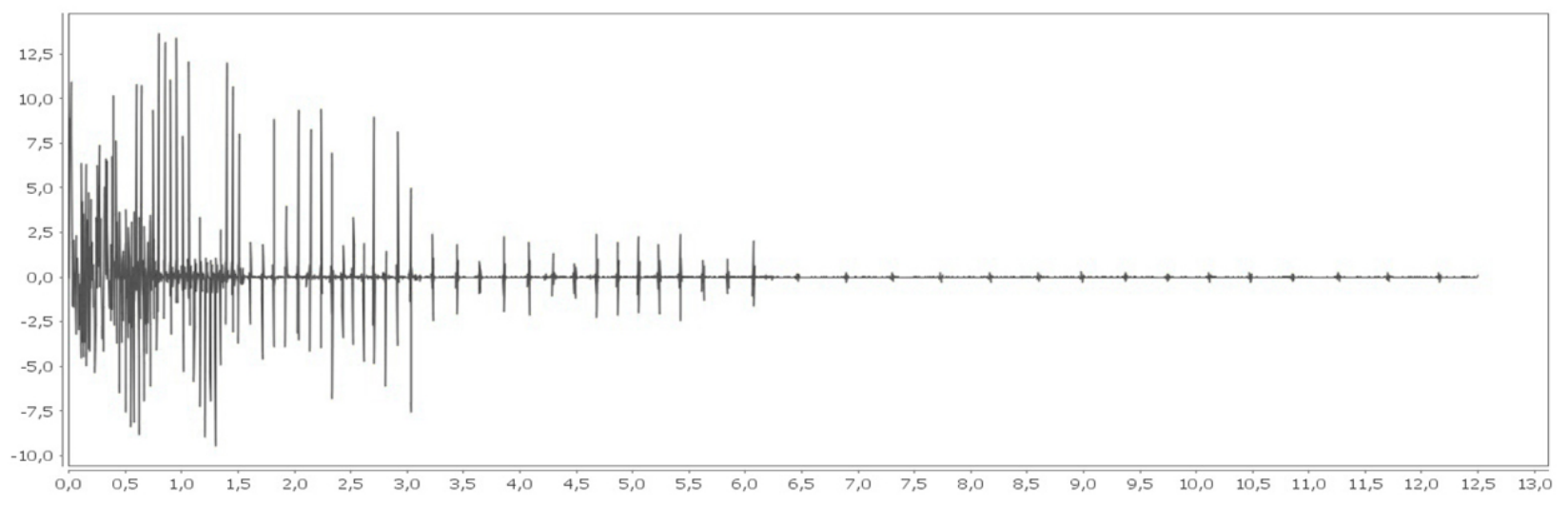

Figure 3: The Symlet function from the ECG data 1

For each volunteer a set of parameters that inform, quantitatively, the individual anxiety trait was generated which allowed us to classify the sample of volunteers in high or low anxiety levels, according to the original propose.

\section{Results}

In Table 1 it is shown which attribute and statistical measure that was applied in the algorithm of data mining, searching for betters results to distinguished each group according to the anxiety levels. ${ }^{[14,26]}$

Table 1: Summary of the characteristics and findings of included studies

\begin{tabular}{llll}
\hline Atribute & $\begin{array}{l}\text { Wavelet } \\
\text { Haar }\end{array}$ & $\begin{array}{l}\text { Wavelet } \\
\text { Symlet }\end{array}$ & $\begin{array}{l}\text { Wavelet } \\
\text { Dauechies }\end{array}$ \\
\hline Pearson Coefficient & Applied & Applied & Not Applied \\
Medium & Applied & Not Applied & Not Applied \\
Mode & Applied & Not Applied & Applied \\
\hline
\end{tabular}

In Table 2, as an example, we present the magnitude of some measures generated by the learning algorithm. The delta value did not change significantly but their values as well others measures, were verified before being discarded.
The procedures can be mathematically explained using as example the Alternating Decision Tree (ADTree) which combine the idea of decision tree to create classification rules based in a set of input parameters, in a simple way: a quantitative rule is stablish if the rule is true, the score is one; otherwise if the rule is false, the score is two. Based on this score, the group is classified.

In Tables 3 and 4 it is shown the same procedure used to generate the results in Table 2 using Smote and Resample methods of training to determine the percentage of settlement. Applying the scale from 0 to 80, which represent the minimal and maximal values obtained in the STAI - T questionnaire, we determined that HTA corresponds to scores bigger than 40. From this, our results indicated the following percentages in our sample: HTA $=37.93 \%$; and LTA $=$ $62.07 \%$. In this case, the low group percentage (37.93\%) was considered the majority error. Thus, to consider the result acceptable the classification errors must be lower than $37.93 \%$. In other words, the result that we desire has a decision tree with settlement classification near to $62.07 \%$. The best methods of classification were those that achieved the maximal values in Tables 3 and 4. Under the protocol adopted in this study it was possible to see that ADTree 
achieves the best score results with lower training percentages, achieving $96.90 \%$ of settlement. Additionally most of algorithms are efficient to classify, however, when the raw data is increased the time training is relevant to determine good precision and less computational time. Thus, in relation to the training, it is possible to see that when the percentage of training is $66 \%$, the LWL values are very simi- lar for SMOTE and Resample. However, when the percentage is $85 \%$, the LWL Resample values increase more than SMOTE LWL values. This fact leads us to consider the Resample method as more indicated to identify the anxiety trait and ADTree as the best classification algorithm considering the both prerogatives: time of computation and reliability.

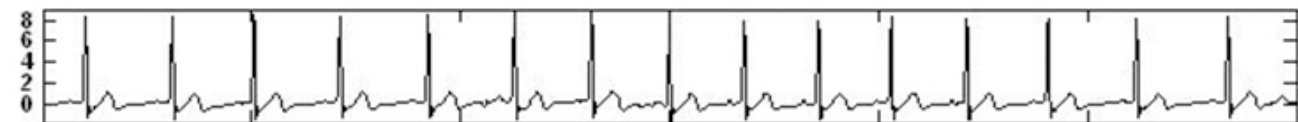

ECG
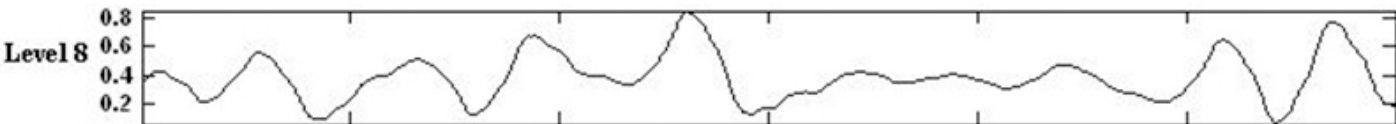

Lever $\begin{array}{r}0.5 \\ 0.5\end{array}$

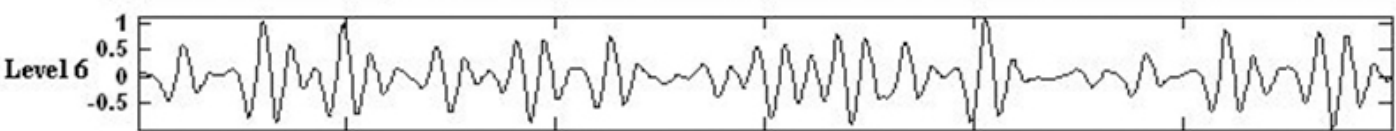

Level 5 :
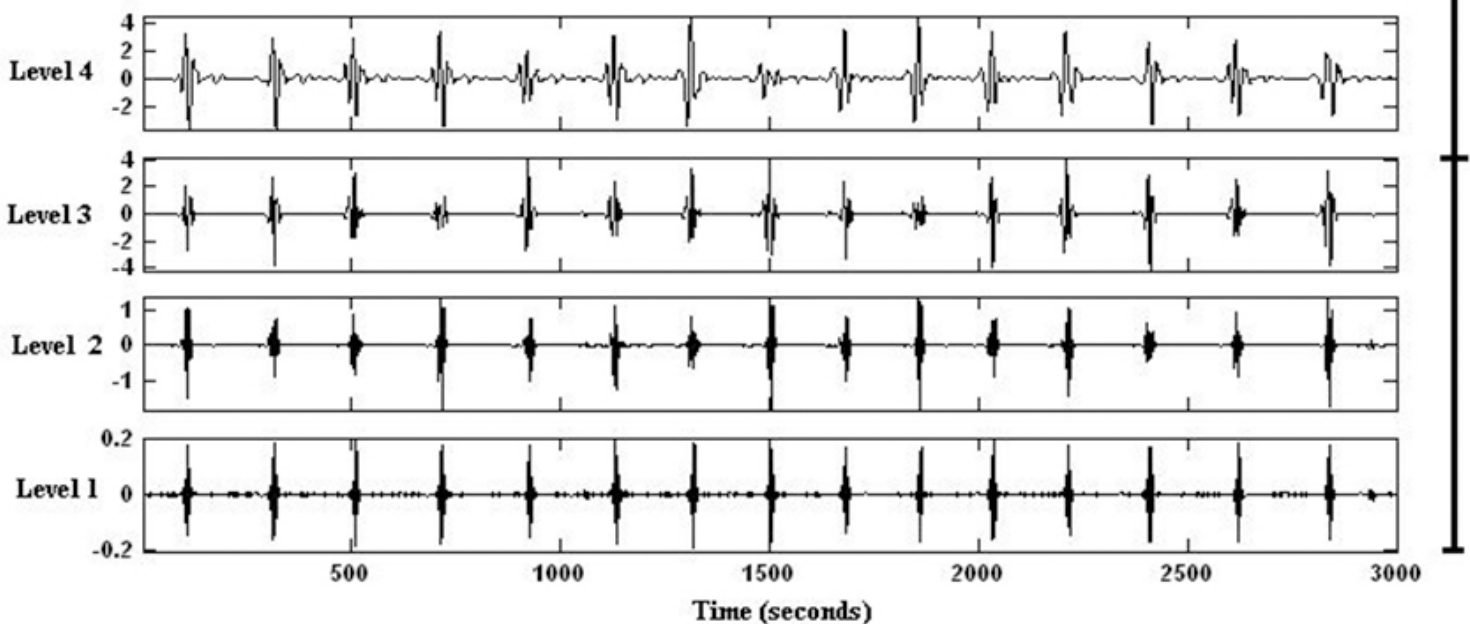

Low

Frequencies

High

Frequencies

Figure 4: The Daubechies function from a complete ECG data, with three different levels of frequency ${ }^{[14]}$

Table 2: Order of magnitude of the measures taken from the processed signal

\begin{tabular}{llllll}
\hline & Person (Symlet) & Mode (Delta) & Mode & Medin (Haar) & Person (Haar) \\
\hline P 1 & 15235 & 0 & -0.004623 & 0.010143 & -38968 \\
P 2 & 40764 & 0.001831 & -0.006212 & 0.003814 & 35060 \\
P 3 & 39452 & 0.012207 & -0.000432 & 0.028501 & 46503 \\
P 4 & 8771 & 0.001831 & 0.003647 & 0.006689 & 14810 \\
P 5 & -193014 & 0.012207 & 0.008639 & 0.011005 & 18054 \\
$\ldots$ & $\ldots$ & $\ldots$ & $\ldots$ & $\ldots$ & $\ldots$ \\
P 29 & 38648 & 0.001831 & -0.00129 & 0.014674 & 553712 \\
\hline
\end{tabular}




\section{Discussion and conclusions}

Our study developed a new set of mathematical tools to characterize anxiety levels independently of questionnaires and other subjective measures. The set of techniques presented here shows that it is possible to generate algorithms that can determine whether a volunteer belongs to a group or to another according to anxiety levels. The wavelet and its statistical measures adopted here were efficient to perform such differentiation. The characterization of individual differences between high and low levels of anxiety has many important uses. As an example, Lang \& Lang $(2010)^{[1]}$ classified two groups of students as high and low anxiety levels, by using a German adaptation of another scale of anxiety, the Test Anxiety Inventory (TAI-G). ${ }^{[27,28]}$ According to this study, test anxiety is an individual and relatively stable trait that is associated with test performance, such as school examinations. In this sense, high levels of test anxiety would be related to a worst performance in school examinations, for example. The authors showed that when high levels anxiety students were identified and submitted to a previous intervention (the so-called "priming competence" intervention - see original text for details) their performance was heightened in a specific intelligent test. The same priming intervention was not efficient in low levels anxiety students; actually their performance was lowered. In the present study we propose a new mathematical tool able to characterize with almost $97 \%$ of reliability, volunteers as high and low anxiety levels. Thus, according to the study previously described, it can also be used to propose new educational strategies to deal with anxiety in the school environment.

Table 3: The percentage of settlement versus the percentage training through SMOTE method

\begin{tabular}{lllll}
\hline $\begin{array}{l}\text { Trainning } \\
\text { (SMOTE) }\end{array}$ & $\begin{array}{l}\text { LWL } \\
\text { (Settlement) }\end{array}$ & $\begin{array}{l}\text { J48 } \\
\text { (Settlement) }\end{array}$ & $\begin{array}{l}\text { ADTree } \\
\text { (Settlement) }\end{array}$ & $\begin{array}{l}\text { RandomForest } \\
\text { (Settlement) }\end{array}$ \\
\hline $66 \%$ & $80.17 \%$ & $77.09 \%$ & $74.34 \%$ & $76.24 \%$ \\
$75 \%$ & $80.25 \%$ & $77.58 \%$ & $79.35 \%$ & $79.15 \%$ \\
$85 \%$ & $81.63 \%$ & $79.71 \%$ & $83.61 \%$ & $82.13 \%$ \\
\hline
\end{tabular}

Table 4: The percentage of settlement versus the percentage training through Resample method

\begin{tabular}{lllll}
\hline $\begin{array}{l}\text { Trainning } \\
\text { (Resample) }\end{array}$ & $\begin{array}{l}\text { LWL } \\
\text { (Settlement) }\end{array}$ & $\begin{array}{l}\text { J48 } \\
\text { (Settlement) }\end{array}$ & $\begin{array}{l}\text { ADTree } \\
\text { (Settlement) }\end{array}$ & $\begin{array}{l}\text { RandomForest } \\
\text { (Settlement) }\end{array}$ \\
\hline $66 \%$ & $80.46 \%$ & $73.41 \%$ & $83.56 \%$ & $82.95 \%$ \\
$75 \%$ & $85.48 \%$ & $76.55 \%$ & $89.05 \%$ & $87.05 \%$ \\
$85 \%$ & $87.05 \%$ & $80.45 \%$ & $96.90 \%$ & $92.55 \%$ \\
\hline
\end{tabular}

The association between HRV patterns and distinct psychological states has already been pointed by others. For example, many authors using groups of subjects suffering from psychiatric disorders, showed that panic disorder or increased anxiety is associated with decreased HRV. ${ }^{[29-33]}$ Despite the majority of the studies have been conducted in clinical populations (individuals diagnosed with anxiety dis- orders) it is quite relevant to investigate cardiac parameters (indices of HRV) also in subclinical populations, which are critically vulnerable to the development of clinical disorders and exhibit similar alterations in psychophysiological parameters. According to this view, in apparently healthy volunteers, anxiety has been associated with total decreased (low-frequency and high-frequency) in heart rate variability. ${ }^{[34,35]}$ also investigated the effect of anxiety in healthy subjects and showed a significant correlation between the STAI-T score and HRV sympathetic modulation. Investigations also have been made on HRV in healthy volunteers that were selected for extreme scores of TA and found that HTA was associated with reduced R-R intervals and high frequency power across conditions. ${ }^{[36]}$ Moreover, a number of neuroscientific studies have employed scales to detect anxiety levels and have associated the scores obtained with hormonal, behavioral, neurophysiological and cardiac parameters. ${ }^{[13,32]}$ Mocaiber and colleagues (2009) showed that HTA individuals are susceptible to modifications in affective contexts. Participants (LTA and HTA individuals) performed an attention task (bar orientation discrimination) while emotional distractive pictures (mutilated bodies) were presented. The task was performed in two different contexts: in the "real" context, participants were informed that the distractive mutilated pictures had been obtained from real life situations, whereas in the "fictitious" context they were informed that the pictures had been obtained from movie scenes. Results showed that the context modulated an electroencephalographic signal (the Late Positive Potential - LPP) obtained during the task: when mutilation pictures were presented in the real context the LPP was larger for HTA; but during the fictitious context the LPP was reduced, even in HTA individuals. Importantly, in all the studies above mentioned scales, the STAI-T was used to separate the samples in high and low anxiety trait. ${ }^{[37]}$

In short, the results obtained in the present study are very promising. They indicate that is possible to separate volunteers according to their anxiety levels (and probably also to other subjective psychological trait) without having to apply any questionnaire or subjective scale. These results based in a physiological measure and its processing show a high reliability when the results are compared with the traditional method, achieving a high percentage of classification success. Besides the use mentioned above, our tools open the possibility of usage in significant amount of mentally impaired patients (such as Alzheimer) or even very young children. How to measure anxiety levels in those patients or in those very young children, if they are not able to read and fully understand the content of such questionnaires? More investigations are necessary to confirm if, actually, our biomathematical predictor can be used to evaluate and classify people according to anxiety levels. ${ }^{[38]}$ Thus, our mathematical tool has important applications in clinical and nonclinical environment, having the advantage that it can be collected without any cognitive intervention. 


\section{Acknowledgements}

The authors acknowledge the support of the Brazilian Agency CNPq (research fellowship) and FAPERJ, Fun- dação de Amparo à Pesquisa do Estado do Rio de Janeiro for financial support.

\section{References}

[1] Lang JWB, Lang J. Priming Competence Diminishes the Link Between Cognitive Test Anxiety and Test Performance: Implications for the Interpretation of Test Scores. Psychological Science. 2010; 21(6): 811-819. http://dx.doi.org/10.1177/0956797 610369492

[2] Maglaveras N, Stamkopoulos T, Diamantaras K, et al. ECG pattern recognition and classification using non-linear transformations and neural networks: a review. International Journal of Medical Informatics. 1998; 52: 191-208. http://dx.doi.org/10.1016/S13 86-5056 (98) 00138-5

[3] Goldman MJ. Principles of Clinical Electrocardiography (12nd ed.). Los Altos, Cal: Lange Medical Publications; 1986.

[4] Leirner AA, Cestari IA. Monophasic action potential. New uses for an old technique. Arquivos Brasileiros de Cardiologia. 1999; 72(2): 208-216. http://dx.doi.org/10.1590/S0066-782X1 999000200010

[5] Kim KK, Kim JS, Lim YG, et al. The effect of missing RR-interval data on heart rate variability analysis in the frequency domain. Physiological Measurement. 2009; 30(10): 1039-1050. http://dx.doi . org/10.1088/0967-3334/30/10/005

[6] Diery A, Rowlands D, Cutmore THR, et al. Automated ECG diagnostic P-wave analysis using wavelets. Computer methods and programs in biomedicine. 2011; 101: 33-43. http://dx.doi.org/1 $0.1016 / \mathrm{j} . \mathrm{cmpb} .2010 .04 .012$

[7] Übeyli ED. Detection of electrocardiogram beats using a fuzzy similarity index. Expert Systems. 2002; 24(2): 87-96. http://dx. doi $. \mathrm{org} / 10.1111 / \mathrm{j} .1468-0394.2007 .00422 . \mathrm{x}$

[8] Übeyli ED. Adaptive neuro-fuzzy inference system for classification of ECG signals using Lyapunov exponents. Computer methods and programs in biomedicine. 2009; 93: 313-321. http://dx.doi.o $\mathrm{rg} / 10.1016 / \mathrm{j} . \mathrm{cmpb} .2008 \cdot 10.012$

[9] Bracewell RN. The Fourier Transform and Its Applications (3nd ed.). New York, NY: McGraw-Hill Book Co.; 2000

[10] Lombardi F, Malliani A, Pagani M, et al. Heart rate variability and its sympatho-vagal modulation. Cardiovascular Research. 1996; 32: 208-216. http://dx.doi.org/10.1016/0008-6363(96)0 0116-2

[11] Boucheham B, Ferdi Y, Batouche MC. Recursive versus sequential multiple error measures reduction: A curve simplification approach to ECG data compression. Computer methods and programs in biomedicine. 2006; 81: 162-173. http://dx.doi.org/10.10 $16 / j . c m p b .2005 .11 .008$

[12] Hung K, Tsai C, Ku C, et al. A linear quality control design for efficient wavelet-based ECG data compression. Computer methods and programs in biomedicine. 2009; 94: 109-117. http://dx.doi.o $\mathrm{rg} / 10.1016 / \mathrm{j} . \mathrm{cmpb} .2008 .08 .007$

[13] Mocaiber I, Pereira MG, Erthal FS, et al. Regulation of negative emotions in high trait anxious individuals: an ERP study. Psychology \& Neuroscience. 2009; 2(2): 211-217. http://dx.doi.org /10.3922/j.psns.2009.2.014

[14] Magini M, Mocaiber I, de Oliveira L, et al. Journal of Biomedical Graphics and Computing. 2012; 2(1): 1-10. http://dx.doi.org $/ 10.5430 / j$ bgc.v2n1p133

[15] Spielberger CD, Gorsuch RL, Lushene RE. Manual for State-Trait Anxiety Inventory. California: Consulting Psychologist Press; 1970.

[16] Biaggio AMB, Natalício L, Spielberg CD. Desenvolvimento da forma experimental em português do inventário de ansiedade traçoestado (IDATE). Arquivos Brasileiros de Psicologia Aplicada. 1977;
29(3): 31-42. http://dx.doi.org/10.1590/S1519-3829200 8000300013

[17] Watson D, Clark LA, Tellengen A. Development and validation of brief measures of positive and negative affect: the PANAS scales. Journal of Personality and Social Psychology. 1998; 54: 1063-1070. http://dx.doi.org/10.1037/0022-3514.54.6.1063

[18] Hall M, Frank E, Holmes G, et al. The WEKA Data Mining Software: An Update. SIGKDD Explorations. 2009; 11: 10-18. http: $/ / \mathrm{dx}$.doi.org/10.1145/1656274.1656278

[19] Chawla N, Bowyer K, Hall L, et al. SMOTE: Synthetic Minority Oversampling Technique. Journal of Artificial Intelligence Researchsea. 2002; 16: 321-357. http://dx.doi.org/10.1613/j air.953

[20] Han J, Kamber M, Pei J. Data Mining: Concepts and Techiniques (1nd ed.). New York, NY: Morgan Kaufmann; 2001.

[21] Varpa K, Iltanen K, Juhola M. Machine learning method for knowledge discovery experimented with otoneurological data. Computer methods and programs in biomedicine. 2008; 91: 2154-2164. http: $/ /$ dx.doi.org/10.1016/j.cmpb.2008.03.003

[22] Järvelin A, Juhola M. Comparison of machine learning methods for classifying aphasic and non-aphasic speakers. Computer methods and programs in biomedicine. 2011; 104(3): 349-357. http: //dx.doi.org/10.1016/j.cmpb.2011.02.015

[23] Ozcift A, Gulten A. Classifier ensemble construction with rotation forest to improve medical diagnosis performance of machine learning algorithms. Computer methods and programs in biomedicine. 2011; 104(3): 443-451. PMid: 21531475. http://dx.doi.org/1 $0.1016 / j . c m p b .2011 .03 .018$

[24] Šajn L, Kukar M. Image processing and machine learning for fully automated probabilistic evaluation of medical images, Computer methods and programs in biomedicine. 2011; 104(3): e75-e86. http://dx.doi.org/10.1016/j.cmpb.2010.06.021

[25] Macfarlane PW, Lawrie TDV. Comprehensive Electrocardiology: Theory and Practice in Health and Disease (1nd ed.). Vols. 1-3, New York, NY: Pergamon Press; 1989.

[26] Machado SM, Osório RAL, Silva NS, et al. Biomechanical analysis of the muscular power of martial arts athletes. Medical \& Biological Engineering \& Computing. 2010; 48: 573-577. http: //dx.doi.org/10.1007/s11517-010-0608-z

[27] Hodapp V, Henneberger A. Test anxiety, study habits and academic performance. In H.M. van der Ploeg. R. Schwarzet, \& C. D. Spielberger (Eds.), Advances in Test Anxiety Research (Vol. 2, pp. 119127). Lisse: Swets \& Zeitlinger; 1982.

[28] Hodapp V, Glanzmann PG, Laux L. Theory and measurement of test anxiety as a situation-specific trait. In C. D. Spielberger \& P. R. Vagg (Eds.) Test anxiety: Theory, assessment, and treatment (pp. 47-59). Washington, D.C.: Taylor \& Francis; 1995.

[29] Middleton HC, Ashby M, Robbins TW. Reduced plasma noradrenaline and abnormal heart rate variability in resting panic disorder patients. Biological Psychiatry. 1994; 36: 847-849. http: //dx.doi.org/10.1016/0006-3223(94) 90596-7

[30] Yeragani VK, Pohl R, Berger R, et al. Decreased heart rate variability in panic disorder patients: a study of power-spectral analysis of heart rate. Psychiatry Research. 1993; 46: 89-103. http: //dx.doi.org/10.1016/0165-1781(93)90011-5

[31] Kawachi I, Sparrow D, Vokonas PS, et al. Decreased heart rate variability in men with phobic anxiety. American Journal of Cardiology. 1995; 75: 882-885. http://dx.doi.org/10.1016/S0002-914 9 (99) $80680-8$ 
[32] Watkins LL, Grossman P, Krishnan R, et al. Anxiety and vagal control of heart rate. Psychosomatic Medicine. 1998; 60(4): 498-502. http://dx.doi.org/10.1097/00006842-199807000-00018

[33] Thayer JF, Friedman BH, Borkovec TD. Autonomic characteristics of generalized anxiety disorder and worry. Biological Psychiatry. 1996; 39: 255-266. http://dx.doi.org/10.1016/0006-3 $223(95) 00136-0$

[34] Piccirillo G, Elvira S, Bucca C, et al. Abnormal passive head-up tilt test in subjects with symptoms of anxiety power spectral analysis study of heart rate and blood pressure. International Journal of Cardiology. 1997; 60: 121-131. http://dx.doi.org/10.1016/S01 67-5273(97) 00088-0

[35] Narita K, Murata T, Hamada T, et al. Interactions among higher trait anxiety, sympathetic activity, and endothelial function in the elderly. Journal of Psychiatric Research. 2007; 41(5): 418-427. http://dx.doi.org/10.1016/j.jpsychires. 2006.01.003

[36] Miu AC, Heilman RM, Miclea M. Reduced heart rate variability and vagal tone in anxiety: Trait versus state, and the effects of autogenic training. Autonomic Neuroscience. Basic and Clinical. 2009; 145: 99-103. http://dx.doi.org/10.1016/j.autneu. 2008.11.010

[37] Fuller BF. The effects of stress anxiety and coping styles on heart rate variability. International Journal of Psychophysiology. 1992; 12: 81-86. http://dx.doi.org/10.1016/0167-8760 (92) 900 $45-\mathrm{D}$

[38] Spielberger CD, Gorsuch RL, Lushene R, et al. Manual for the StateTrait Anxiety Inventory. Palo Alto, CA: Consulting Psychologists Press; 1993 